\title{
The Five Functions of Forensic Science and the Validation Issues They Raise: A Piece to Incite Discussion on Validation
}

\author{
D. Michael Risinger*
}

I.INTRODUCTION .719

II.WHAT IS THE OPERATIONAL ASSUMPTION CONCERNING THE MEANING OF "FORENSIC SCIENCE" REFLECTED BY THE OSAC EFFORT?. 720

III.THE FIVE FUNCTIONS OF FORENSIC SCIENCE............................... 724

A. Description/Characterization of an Object .....................724

B. Identification of a Substance or Object ..........................725

C. Association of One Object With Another.......................727

D. Source Attribution ........................................................... 729

E. Reconstruction of a Dynamic Event ................................731

1. Simple Reconstruction Expertise.............................731

2. Complex Reconstructive Expertise-Utilizing a Variety of Information, Some Self-Derived, Some Obtained from Other Sources, to Reconstruct the Evolution of a Dynamic Event

\section{INTRODUCTION}

In mid-February of 2017, I attended (virtually) the meeting of the whole National Institute of Standards and Technology (NIST) Organization of Scientific Area Committees for Forensic Science (OSAC), at which every area of forensic science covered by the various Scientific Area Committees (SACs) and their subcommittees reported on the current state of their efforts to bring improvement to their respective disciplines. This exercise caused me to reflect on two questions-what is the operational assumption concerning the meaning of "forensic science" reflected by the OSAC effort, and what can be said about approaches to validation in regard to the disparate collection of disciplines covered by the OSAC subcommittees? I will address each of these questions below.

* John J. Gibbons Professor of Law, Seton Hall University School of Law. 


\section{WHAT IS THE OPERATIONAL ASSUMPTION CONCERNING THE MEANING OF "FORENSIC SCIENCE" REFLECTED BY THE OSAC EFFORT?}

In approaching this question, I will not take up the hugely contentious issue of the "demarcation problem," that is, the proper criteria to be used to distinguish between claims of expert knowledge based on "science," and those based on non-science (but perhaps still well-warranted) knowledge. ${ }^{1}$ Instead, I will simply set out what appears to be the OSAC operational assumption, which is a very broad approach to the notion of science in forensic science - one that apparently reflects the traditional forensic science usage in labelling something "science" if the practitioners in an area have asserted historically that they are "scientists" whose knowledge has been derived "scientifically." It is clear that something like this broad a definition is at work in the OSAC, because it includes many disciplines that would be hard put to meet any more constrained definition of "science-based knowledge" but which for many decades have been claimed by their practitioners to reflect the products of "science."

The "forensic" part is also a little troublesome to characterize. The usual definition of "forensic science" is "the application of scientific knowledge to provide relevant evidence for use in the determination of material issues in resolving legal disputes," or some such. ${ }^{2}$ Viewed from this broad perspective, virtually any scientific knowledge can be deployed as "forensic science" in some litigation setting. ${ }^{3}$ For instance, quantum mechanics might provide relevant information on why some GPS system was in error in a way that caused damage to users of that system. Obviously, this broad definition is not the operational definition for the OSAC. Quantum physicists might become expert witnesses on occasion, but the (perfectly reasonable) operational assumption of the OSAC is that the forensic science disciplines it will deal with will be limited to disciplines whose products are predominantly if not exclusively generated for use in

1 I have put in my two cents worth on this in D. Michael Risinger, The Irrelevance, and Central Relevance, of the Boundary Between Science and Non-Science in the Evaluation of Expert Witness Reliability, 52 VILL. L. REV. 679, 698-712 (2007).

2 Am. Acad. of Forensic Sci., About AAFS, https://www.aafs.org/about-aafs/ (last visited Feb. 17, 2018) (quoting the 1993 AAFS Board of Directors stating: "Forensic Science is the application of scientific principles and technological practices to the purposes of justice in the study and resolution of criminal, civil, and regulation issues").

3 "There is literally no end to the number of disciplines that become 'forensic' by definition. Nor is there an end in sight to the number of present or future specialties that may become forensic. The examples are many.” BETTY LAYNE DESPORTES \& ANNE WARREN, AM. ACAD. OF Forensic SCI., So You WANT to Be a Forensic Scientist! 27 (2014), https://ww w.aafs.org/wp-content/uploads/FSF_CareerBrochure_2014Edition.pdf (quoting Anthony Longhetti, Editorial, 28 J. FORENSIC SCI. 3, 3 (1983)). 
litigation in courts or other similar fora, or the investigation of such issues. ${ }^{4}$ But still this definition is too broad, because many disciplines whose products have recurring impact on many issues in civil litigation, such as epidemiology in toxic tort claims, are nowhere to be found in the OSAC. It is clear that the focus of the OSAC is on forensic science disciplines whose products are generally aimed at criminal litigation, even though they may also be relevant to various civil claims. ${ }^{5}$ This practical focus is the result both of the historical membership in the American Academy of Forensic Sciences, and of the origins of the OSAC effort-the 2009 NAS report, which was focused on problems of reliability in regard to forensic science, specifically prosecution-proffered forensic science, in criminal proceedings. Even through this lens, however, there are some curious omissions from the OSAC. Forensic pathologists and forensic dentists are included, but forensic psychologists and psychiatrists, even though they also invoke the mantle of science, are not included. Perhaps this omission was more a matter of prudence than of principle, given the hugely different problems of standardization and validity presented by those "forensic science" disciplines. It is hard to imagine the kind of standards effort and products fostered by NIST being generated in regard to forensic psychology and psychiatry. Or perhaps it was merely a matter of habit, since the term "forensic science" is not commonly deployed in regard to them. ${ }^{6}$

Be that as it may, there are still plenty of disciplines that are included. Here is a list of specialties which may be incomplete, depending on how one cuts domain boundaries, but is still extensive and good enough for illustrative purposes:

4 The AAFS has a "general" section to cover people who seek membership whose disciplines are not covered by the main sections, which are Anthropology, Criminalistics, Digital and Multimedia Sciences, Engineering Sciences, Jurisprudence, Odontology, Pathology/Biology, Psychiatry and Behavioral Sciences, Questioned Documents and Toxicology. Am. Acad. of Forensic Sci., Membership, https://www.aafs.org/membership/ (last visited Feb. 17, 2018). One should not try to derive any great principle to account for the subject matter in these sections. "Criminalistics" covers a multitude of disciplines, including serology but not blood spatter, which is covered by the "general" section. DNA analysis ended up in criminalistics with serology instead of both of them being in "pathology/biology" where they would appear to belong. The general section occasionally spawns new primary sections.

5 For instance, forensic engineering sciences has no OSAC subcommittee, even though a section of the American Academy of Forensic Sciences (AAFS) is devoted to it.

6 I say this even though the AAFS actually has a section for Psychiatry and Behavioral Sciences. Indeed, the Psychiatry section was one of the charter sections of the organization when it was first officially organized in 1949. See KATHERINE RAMSLAND, BEATING THE DEVIL's GAME: A History OF FoRENSIC SCIENCE AND CRIMINAL INVESTIGATION 201 (2007). It is interesting to note that the AAFS website gives 1948 as the date of founding, but the 1948 meeting was in fact an ad hoc meeting which led to the actual founding and naming of the AAFS the next year. See Am. Acad. of Forensic Sci., About AAFS, https:/www.aafs.org/abo ut-aafs/\#aafs-history (last visited Feb. 17, 2018). 
Forensic document examination (mainly but not exclusively

handwriting analysis)

Fingerprint examination (friction ridge analysis and comparison)

Other print-like phenomena

Footprints

Tire tracks

Visual hair and fiber comparison

Firearms expertise

Toolmark expertise

Blood stain and spatter analysis

Forensic odontology

Forensic anthropology

Forensic entomology

Forensic botany

Forensic biological morphology

Forensic geology

Forensic serology

Human DNA

Non-human DNA

Forensic toxicology

Forensic chemistry (includes gunshot residue)

Dogs as instruments to identify and find substances

Digital forensics

Photogrammetry

Facial Recognition

Voice recognition

Fire investigation

Shooting incident reconstruction

Forensic pathology

The above list is merely illustrative of the variety of disciplines covered by the OSAC. Some of the labels cover areas that are very narrow in their focus and the subject matter they deal with. For instance, fingerprint examiners deal almost exclusively with the characterization and comparison of fingermarks left at a crime scene with exemplars from known people, either individually or identified through a database search. That is not to say that there are not different contexts and subtasks involved in the enterprise, but they all revolve around the phenomenon of ridged skin. Document examination, on the other hand, encompasses a more complicated subject matter. While the bulk of a document examiner's work involves comparison of handwriting of various kinds, document examiners also deploy expertise 
in regard to paper, ink, printing methods, and other specialized knowledge relevant to determining the authenticity of any sort of document.

However, my purpose is not to describe in detail the broad or narrow domain of the disciplines listed above. Instead, I want to suggest that the tasks of all these disciplines fall into a very few categories, and that those cross-discipline categories have something to teach about what validation is necessary to determine if their claims to knowledge are "fit for purpose," especially in regard to prosecution-proffered expert testimony in criminal cases. Note that my observations below are limited to what might be called "ideal condition validity." The validity of results under the actual conditions of practice prevailing at the time of the generation of the result is another topic altogether, although an important one, which I invite other participants in this symposium to explore. ${ }^{7}$

7 "Actual practice validity" differs from "ideal condition validity" because of various non-ideal conditions that may prevail in the environment of actual practice that can influence the results of examinations to become much more inaccurate than established "ideal condition validity" might suggest. The terms used here seem to be synonyms for the terms "foundational validity" and "validity as applied," used in the report to the President of the President's Council of Advisors on Science and Technology (PCAST). See PrESIDENT's COUnCIL of Advisors on SCI. \& TeCh., Report to THE PREsident: Forensic SCIENCE IN Criminal COURTS: EnSURING SCIENTIFIC VALIDITY OF FEATURE-COMPARISON METHODS 4-6 (2016), https://obamawhitehouse.archives.gov/sites/default/files/microsites/ostp/PCAST/pca st_forensic_science_report_final.pdf. The distinction was first suggested (without the labels) in 2002 in the context of handwriting identification in the following passage from D. Michael Risinger, Handwriting Identification, in 3 MODERN SCIENTIFIC EVIDENCE: THE LAW AND SCIENCE OF EXPERT TESTIMONY 400-83 (West, 2d ed. 2002):

What is more important, however, are the gross potential differences in document examiner performance between test conditions and real conditions of practice. Put simply, document examiner performance under test conditions is likely to be the best performance of which they are capable, and therefore error rates are likely to the lowest possible error rates under ideal conditions which do not apply to the real world.

Id. The environment-of-application factors that are likely to degrade accuracy can be usefully divided into "biasing factors," (including both failure to control domain-irrelevant biasing information and other institutional influences such as law-enforcement team identification, etc.), and "structural factors," such as the hiring and retention criteria used to insure competence, the size of workload, the documentation and review structure meant to insure integrity of individual results, etc. The latter issues are the main focus of the discipline of "error studies," pioneered by James Reason and others. See JAMES REASON, HumAn ERROR (1990); D. Michael Risinger, Whose Fault?-Daubert, the NAS Report, and the Notion of Error in Forensic Science, 38 FordHAM URB. L.J. 519 (2010). The former issues are dealt with extensively in D. Michael Risinger, Michael J. Saks, William C. Thompson \& Robert Rosenthal, The Daubert/Kumho Implications of Observer Effects in Forensic Science: Hidden Problems of Expectation and Suggestion, 90 CAL. L. REV. 1 (2002). See also Dan E. Krane et al., Sequential Unmasking: A Means of Minimizing Observer Effects in Forensic DNA Interpretation, 53 J. Forensic SCI. 1006 (2008). See, e.g., Itiel E. Dror \& David Charlton, Why Experts Make Errors, 56(4) J. ForENSIC IDENTIFICATION 600, 600-16 (2006); Itiel E. 


\section{THE FIVE FUNCTIONS OF FORENSIC SCIENCE}

I believe every task undertaken in a forensic science discipline will fall into one of five categories:

1. Description/characterization of an object

2. Identification of a substance or object

3. Association of one object with another by virtue of common characteristics

4. Source attribution (This is a special class of association springing from the claim that some associations may be so strong as to justify identifying one as the source of the other, or concluding that both had the same source.)

5. Reconstruction of a dynamic event

\section{A. Description/Characterization of an Object}

The first category, description/characterization of an item, is actually a low-level task sometimes on the borderline between an expert and nonexpert function. Essentially, it involves pointing out or documenting sensory characteristics of an item (usually visual) which are relevant to a low-level expert characterization. By low-level, I mean only that it is easily explained and understood, and relatively transparent to a non-expert when explained.

For instance, consider the description of a particular kind of gouge or mark on the rim of a shell casing, together with its characterization as an ejector mark, that is, a mark left by the ejector in an automatic or semiautomatic weapon when a round goes through the chamber from the magazine and is then ejected to clear it from the firing chamber, usually to make way for the next round. ${ }^{8}$ If you or I examined the shell casing under appropriate conditions of lighting, and perhaps magnification, we would no doubt be capable of seeing the mark, but we might not note it because we would not know its significance. When the mark is pointed out to us, we will see it. When the mechanism is explained and demonstrated to us, we will then understand the genesis of such a mark. Here, "validation" is provided by the phenomenon, the demonstration, and the understanding of

Dror, Cognitive Forensics and Experimental Research About Bias in Forensic Casework, 52 SCI. \& JUST. J. 128, 128-30 (2012); Itiel E. Dror, Saul M. Kassin \& Jeff Kukucka, New Application of Psychology to Law: Improving Forensic Evidence and Expert Witness Contributions, 2 J. Applied Res. Memory \& Cognition 78, 78-81 (2013); Itiel E. Dror, Practical Solutions to Cognitive and Human Factor Challenges in Forensic Science, 4(3-4) Forensic SCI. Pol'y \& MGMT. 105, 105-113 (2013).

8 See FirearmsID.com, Striated Action Marks, http://www.firearmsid.com/A_CCIDStri a.htm (last visited Feb. 17, 2018). 
the (relatively simple) mechanism. In addition, it is also sufficiently clear that the imposition of a confusably similar mark on the rim of a shell casing by some other mechanism than an ejector is an event of very remote likelihood. Critical common sense and the nature of the specific phenomenon being described and characterized provide sufficient reason to believe the validity of the characterization.

Such may not be true for all description/characterization tasks. Some may be more difficult tasks which cannot be rendered by explanation quite so transparent to the ordinary person, and thus require some more formal validation of the ability of the expert to make the characterization with sufficient accuracy for purpose, including some description of the possibilities for error. For example, in rare instances an ejector may be worn in such a way as to leave a less clear and more ambiguous mark, and therefore, when dealing with such an unclear mark, some formal study of the threshold of confidence for the characterization under such conditions might be desirable. But this merely illustrates the inescapability of viewing the validity of expert assertions in the context of the specific expert task presented by the evidence, ${ }^{9}$ and in no way detracts from the critical common sense validity of the ordinary characterization of a clear mark as an ejector mark. And I believe it is instructive to have begun with an example where the characterization is such as to be virtually self-validating, given the nature of the phenomenon involved, a background circumstance in regard to many components of many disciplines which is often overlooked by enthusiasts and sceptics alike.

\section{B. Identification of a Substance or Object}

This is a task which might be called "characterization on steroids." It involves the determination that a substance or object falls into a specific taxonomic category of legal significance. It most commonly involves drugs or other contraband, but may also involve the determination of the presence of substances in the body that are poisons or drugs or in some other way relevant to a case. Note also that almost all the techniques deployed in accomplishing this, no matter the substance or item or particular discipline, are generally going to qualify as the products of science by anyone's definition, and will often be heavily instrumented. This is the task associated

9 Mark P. Denbeaux \& D. Michael Risinger, Kumho Tire and Expert Reliability: How the Question You Ask Gives the Answer You Get, 34 Seton Hall L. REv. 15, 31-60 (2003); D. Michael Risinger, Defining the "Task at Hand": Non-Science Forensic Science After Kumho Tire Co. v. Carmichael, 57 WASH. \& LEE L. REV. 767 (2000); D. Michael Risinger, Goodbye to All That or a Fool's Errand, by One of the Fools: How I Stopped Worrying About Court Responses to Handwriting Identification (and "Forensic Science" in General) and Learned to Love Misinterpretations of Kumho Tire v. Carmichael, 43 Tulsa L. REv. 447 (2007). 
with forensic chemistry, with heavily instrumented and computerized technologies such as gas chromatography, mass spectroscopy, scanning electron microscopy, energy-dispersive x-ray spectroscopy and many others, or with forensic biology when dealing with contraband ivory and other animal substances, etc. It is also the task involved in DNA typing. In these instances, we can expect ordinary scientific validation of most processes utilized, and certainly the instrumented processes, to have been done in the normal course by well-understood regimes of validation testing, since many of the techniques and instruments are in everyday use in scientific research settings beyond the specifically forensic context. This is not to say there are no validity issues specific to this kind of process when utilized in the forensic setting. Various statistical and computerized approaches to the characterization of mixed DNA samples provide good examples because the issue they address arises primarily in forensic work. Nevertheless, normal validation testing for such processes ought to be expected and required before the processes are utilized in case work.

Further, there are often residual validity issues in regard to such identification tasks even when the instrumented component is well validated. As previously noted, some processes are sufficiently automated so that their results require very little human interpretation. But more commonly, there is a human interpretive facet to the process, either at the front end in selecting the manner in which the instrumented process is to be deployed, or at the back end in interpreting the output of the instrumented component. Sometimes the deployment criteria are fixed and their reasons transparent, and sometimes the instrumented outputs are so unambiguous as to require little interpretation and present little room for error. In such circumstances, critical common sense can suffice to validate the human part of the process. But when these conditions are not present, the human judgment components themselves require validation if one is to speak of the validity of the final product of the process, which is of course the ultimate validity question we care about. It seems appropriate here to note that the volume and repetitive nature of much of this work, and the temptations flowing from the ease of faking results, has led to many scandals, but this is really a human factors and management problem, not a validity problem, at least not an "ideal conditions validity" problem of the sort that is the focus of this piece. ${ }^{10}$

Even in substance identification situations, there are some tasks for which human judgment is used as the primary modality, sometimes for reasons of perceived cost or efficiency advantage. An interesting example is presented by the identifications of birds and bird parts as being contraband because they come from endangered or otherwise protected species. There

\footnotetext{
10 See supra note 7. These factors do present serious "validity as applied" issues.
} 
are currently two available sources of expert information-morphological identification by a forensic ornithologist, or avian DNA testing. The United States Fish and Wildlife Service currently uses the forensic ornithologist at its National Fish and Wildlife Forensics Laboratory, Dr. Pepper Trail, to make these identifications, instead of resorting to DNA. As a recent news story reported, the Laboratory has "DNA-sequencing technology that seems fit for an episode of CSI," but:

Trail's tactics, however, are decidedly more analog. He's a morphologist who makes identifications by carefully studying and comparing anatomical characteristics of different bird parts. In most cases, this approach is not only faster and cheaper than booting up the sequencers and calling the genetics team, it's also equally effective. It has to be. Much like forensic evidence in a murder trial, the science behind Trail's work needs to withstand the scrutiny of aggressive defense attorneys, diligent judges, and impartial juries. ${ }^{11}$

I am sure that the identifications done by Dr. Trail often present clear and simple tasks for a morphologist which are unlikely to result in errors. On the other hand, there are bound to be some judgments that are harder and more contestable. In the face of such a challenge, in the laboratory or in court, it is good to have DNA as a backup even if it is not automatically used as the primary method of testing. ${ }^{12}$

\section{Association of One Object With Another}

I have separated "association" from "source attribution," which division generally maps on to the traditional forensic science distinction between "class characteristics" and "individual characteristics," but I am not at all comfortable with this latter dichotomy. In fact, as central as this dichotomy is to the rhetoric of many forensic disciplines, I think it often causes confusion and does more harm than good, and should be abandoned. As a general matter, all characteristics are class characteristics - the real issue is, what is the size of the class defined by the characteristics at issue.

11 Chris Sweeney, The Dead Bird Detective, WEEK (Feb. 5, 2017), http://theweek.com/ articles/677652/deadbird-detective.

12 This raises the question of which tests should be treated as presumptive tests for investigation only, and which as fit-for-purpose for courtroom testimony. For instance, the reactions of trained dogs in alerting to drugs or other substances is currently treated only as a presumptive test, and will generally be seen in court only in regard to issues of probable cause to search. Whether this or any other presumptive test should be admitted against a criminal defendant in the absence, explained or otherwise, of more diagnostic testing, is beyond the scope of this writing. 
Traditional approaches to this question in forensic science have proceeded on the assumption that there was a substantial and important conceptual and phenomenological space between "individual characteristics," which were assumed to define a class of only one in the universe, and all other characteristics, which might be shared with some other undefined number of items, and therefore were merely "class characteristics." This extreme separation into two dichotomous categories of what is really a continuous phenomenon has led to many unnecessary and overbroad claims concerning "uniqueness." There is a robust literature on the vices of this approach. ${ }^{13}$ Suffice it to say that "uniqueness," which is intuitively attractive on one level, is a concept that neither lends itself to empirical demonstration, nor is it necessary to allow fully warranted inferences of common source beyond reasonable doubt. Nevertheless, I find it useful to divide circumstances where evidence is being proffered to invite or warrant an inference of common source, from those where the proffered evidence is conceded not to provide, in and of itself, a strong basis for inferring that one particular item was the source of a particular mark or residue based on their shared characteristics, but merely to show that they share common characteristics, and that the one cannot be excluded as a source of the other (or of their being the product of a common source).

For example, it is often conceded in a particular case that all that can be done with a tire tread mark at a crime scene is to describe the pattern, to determine the make of the tire that carries such a pattern by reference to a reference collection of tread designs, and to say that a particular car also has tires of such a design and make. By itself all this does is say that the coincidence is simply as meaningful as the base rate of such tires in the local tire population, ${ }^{14}$ which is likely not to be very diagnostic of common origin in itself, and easily understood not to support such an inference by itself (although it might form one part of a persuasive circumstantial package when combined with other, independent information). When it is clear that no claim is being made that the correspondences are diagnostic enough by themselves to infer that the defendant's tire made the track, the evidence is

13 See Mark Page, Matt Blenkin \& Jane Taylor, Uniqueness in the Forensic Identification Sciences-Fact or Fiction?, 206 ForENSIC SCI. INT'L 12 (2011); D. Michael Risinger \& Michael J. Saks, Science and Nonscience in the Courts: Daubert Meets Handwriting Identification Expertise, 82 IowA L. REV. 21, 39-40 (1996) (analyzing what are functionally uniqueness claims in handwriting identification). David H. Kaye, Probability, Individualization, and Uniqueness in Forensic Science Evidence, 75 BROOK. L. REV. 1163 (2010) (including authorities there cited); Michael J. Saks \& Jonathan J. Koehler, The Individualization Fallacy in Forensic Science Evidence, 61 VAND. L. REV. 199 (2008).

14 One could argue that provision of some sort of base rate information should be a part of the proffer, but it seems to me that juries without more are unlikely to think a mere tread pattern is rare, and thereby overvalue the diagnostic weight of the evidence, if no information is given. 
often as "self-validating" as the ejector mark characterizations described above.

\section{Source Attribution}

Here is where the rubber meets the road, for the tire example above, and for all other claims that a crime scene residue carries some sort of tagged information of sufficient specificity that it can allow a reasonable person to find it was made by a particular tire (or other source) beyond reasonable doubt. This is the forensic science function that has had the most ink spilled about it in the last twenty-five years or so. It has been an especially contentious subject because much of the evidence proffered as justifying a well-warranted inference of common origin has come from disciplines with weaker claims to scientific knowledge than chemistry, etc., and with a paucity of formal validation. I have contributed perhaps more than my share to this ocean of ink. I can make my points about validation in regard to this function most efficiently by quoting myself. When it comes to such claims, validation must be done by proper and reliable information, but

[b]y "proper and reliable information" I do not necessarily mean the generation of formal data sets that yield proper quantified statistical information bearing on validity. Not every belief about the reliability of a process must be based on such data, and indeed, if we absolutely required such data, we should have to abandon many bases of inference that are well warranted by critical common sense. In this regard, I am not an acolyte of the great nineteenth century physicist Lord Kelvin, who claimed that only such formal quantified measurement could count as knowledge worth anything. To Lord Kelvin, I say, behold this broken tea bowl. The perfect puzzle fit of the fracture, corroborated by the continuity of the design, would warrant beyond-reasonable-doubt confidence that the two were once part of a single bowl, without formal data on random match probabilities. It seems clear, at least in vitreous materials like glass and porcelain, that fracture involves random forces that generate so many points of unpredictable and difficult- or impossible-to-reproduce correspondence that the inference of common source approaches certainty very closely. On the other hand, one must be extremely careful in making such claims. For instance, correspondences in regard to fracture or tear in other materials may be much less indicative of common source. And I can construct (in fact have published) a version of the vitreous fracture argument that works well in regard to the accuracy of common source inferences using rolled fingerprints, but much less well or not at all as one begins to deal with the problems of small or smudged latent prints. The 
burden of persuasive explanation should always be on those relying on such non-quantified claims to justify the reliability of expertise absent formal data. This is because humans can be subject to a lot of wishful thinking and exaggerated self-belief for which formal data is a great corrective, besides being valuable in itself. For this reason, reliability assessments based on formal data from well-designed and appropriate studies are to be preferred, pursued, and cherished, even though it is often, perhaps usually, very difficult, expensive, and time-consuming to generate such data, requiring great care in study design and sensitivity to the fact that each sub-task in an area of claimed expertise must be identified and subjected to separate study. And as Jennifer Mnookin, Michael Saks, and I have pointed out repeatedly in various places, such data does not necessarily have to be pointed toward the development of random match probability models, at least in the first instance. ${ }^{15}$ Properly designed "black box" studies of the success or failure of practitioners under different test conditions can yield useable data bearing on the reliability of expert results, which can fill the gap between no formal reliability data and the much more difficult task of generating DNA-like statistical systems. ${ }^{16}$

Today I think it can be rightly said that the need for formal validation for many forensic science applications is well established and fairly generally recognized. After the issuance of the NAS Report, most of the leaders of the forensic science establishment have conceded the necessity of such validation, in order to quiet criticism if nothing else. Even while admitting this, however, there remain those who proclaim that such validation is a mere technical detail which will show that everything done in the name of forensic science heretofore has always yielded accurate results, at least when the results were derived by properly trained individuals adhering strictly to the procedures set out by the best authorities in the area, and all that is really required to eliminate error is laboratory accreditation and examiner certification. This has been a recurrent theme in the response of the forensic community to the NAS Report. In my opinion, this is almost certainly the product either of a public relations instinct or wishful thinking

15 See, e.g., Jennifer L. Mnookin, Of Black Boxes, Machines and Experts: Problems in the Assessment of Legal and Scientific Validity, 5 EPISTEME 343 (2008); Michael J. Saks, Remediating Forensic Science, 48 JURIMETRICS J. 119, 124 (2007); Michael J. Saks, The Aftermath of Daubert: An Evolving Jurisprudence of Expert Evidence, 40 JURIMETRICS J. 229, 239 (2000); D. Michael Risinger, Preliminary Thoughts on a Functional Taxonomy of Expertise for the Post-Kumho World, 31 Seton Hall L. Rev. 508, 522 (2000); Risinger \& Saks, supra note 13, at 40-41.

16 Risinger, Whose Fault?, supra note 7, at 540 (internal footnotes omitted except for renumbered note 15 , supra). 
or both. In the traditional forensic identification disciplines, as in folk medicine, careful testing of the claims is virtually certain to find areas of unreliable performance, just as there are likely to be many areas of reliable performance. The path forward from here to reliable knowledge of the accuracy of the various such disciplines in all their many claims will involve a lot more research than people have been willing to admit or contemplate up to now. It will take years, and "will require the full and committed cooperation of the forensic science community. I believe that full and committed cooperation is an ethical obligation." 17

I wrote that in 2010 , before the OSAC was created. I believe that the studies I thought were necessary then are now starting to be widely accepted as necessary, and are slowly starting to be done. The danger, I think, is that too few of them will be done and those few will then be taken to give validation more broadly to more tasks in an area than they actually apply to. In addition, exactly how diagnostic the valid results of a forensic examination must be to warrant a source conclusion by the examiner (or by the trier of fact beyond reasonable doubt, which is perhaps a separate issue) is in itself a complex question, and something I will not address here.

\section{E. Reconstruction of a Dynamic Event}

One thing that I believe has been under-appreciated, however, are the validity problems presented by the final category on my list, which we may call event reconstruction expertise. This function goes beyond mere identification/categorization, and beyond association, to provide evidence that warrants an inference of how a dynamic event unfolded. It is useful to divide this function further into two sub-categories, which, for want of better terms, I will label "simple" and "complex."

\section{Simple Reconstruction Expertise}

Sometimes fairly simple specific observations are reasonably diagnostic of an important aspect of how a dynamic event unfolded. For instance, the characterization of a bullet wound as an entry wound gives important information about the relative positions of the shooter and the victim when the shot was fired. Another example would be the existence of a specific kind of flow damage on a recovered bullet (styled "bow effect" damage by firearms experts), ${ }^{18}$ which is diagnostic of ricochet off of or through abrasive but yielding material such as hard-packed soil. Indeed, the entire area of blood stain and spatter analysis is directed to the characterization of the blood stain patterns at a scene with an eye to inferring

17 Risinger, Whose Fault?, supra note 7, at 541-42.

18 Michael G. HAAG \& LUCien C. HAAG, ShoOting InCident ReCONSTRUCTION 163-65 (2d ed. 2011). 
various aspects of the unfolding of the event that resulted in the bloodstains and spatter. I still count this as "simple" for current purposes, however, (even though the patterns and resulting inferences can be quite complex) because it deals with the characteristics of a single evidentiary phenomenon.

2. Complex Reconstructive Expertise-Utilizing a Variety of Information, Some Self-Derived, Some Obtained from

Other Sources, to Reconstruct the Evolution of a Dynamic Event

This function is radically different from all the other expert functions we have discussed, in a number of ways. Here the expert is claiming to be able, not merely to characterize objects (although that too), and not merely to identify objects as belonging to legally relevant categories (although usually that too), and not merely to associate a residue with a source (although often that too), but to take the expert's own expertise in those regards, and combine it with relevant expert conclusions from other disciplines (such as forensic chemistry, toxicology, forensic anthropology, etc.), and perhaps other non-expert information as well, and reach expert (not merely ordinary intelligent factfinder) conclusions on the way an event in the past happened or unfolded. Sometimes there are claims by such experts that they need all available information to guarantee maximal accuracy of results, but such a claim merely disregards rather than defines and observes the actual borders of their claim to specialized knowledge and expertise. Such expert claims and functions present special problems of validation, and also special problems of control, so that they do not become merely ordinary factfinders operating under a claimed expert umbrella, and thereby going beyond any defensible claim of actual expertise and invading the province of the ordinary factfinder under the guise of expertise. Examples of such expert disciplines include fire investigation, shooting incident reconstruction, forensic pathology, and forensic engineering. Each of these areas presents its own challenges in terms of validation and proper control. Exactly how best to approach each such discipline is beyond the scope of this Article. As to this and other points set out in this Article, I hope it will be regarded as enough to have provided something of a fresh view, and perhaps to have aided further exploration. 